\title{
La gestión por las Temporalidades de los esclavos de las antiguas haciendas jesuíticas (Perú, 1768-1815). Algunos aspectos socio-económicos
}

por

Jean-Pierre Tardieu ${ }^{1}$

Université de La Réunion

En el Perú la capacidad económica de los siervos de la Compañía les permitió, a no pocos, rescatarse, después de la expulsión. Entre las víctimas de los traslados a otro fundo de las Temporalidades, el apego al terruño suscitaba un cimarronaje de proximidad. En cuanto a los «brazos inútiles», su venta se integró en una red comercial, que se extendió por el cono sur.

En caso de abusos en contra de los esclavos de haciendas arrendadas o de esclavos vendidos a particulares, las Temporalidades ejercían una especie de patronato. A este respecto, las mujeres desempeñaban un papel de primera importancia en las reivindicaciones colectivas.

Palabras Clave: Perú; jesuitas; expulsión; esclavos; Temporalidades; 1768-1815.

Cómo CITAR ESTE ARtículo / Citation: Tardieu, Jean-Pierre, «La gestión por las Temporalidades de los esclavos de las antiguas haciendas jesuíticas (Perú, 1768-1815). Algunos aspectos socio-económicos», Revista de Indias, LXXIX/277 (Madrid, 2019): 797-826. https:// doi.org/10.3989/revindias.2019.023.

En dos trabajos sobre los esclavos de las haciendas jesuíticas del Perú y del Río de la Plata expuse los resultados de la política de la Compañía en materia de mano de obra servil en sus fundos agrícolas y diversas posesio$n e s^{2}$. En un estudio anterior acerca de sus antiguas fincas de la Real Audien\footnotetext{
1842.

1 jean-pierre.tardieu@univ-reunion.fr, ORCID iD: https://orcid.org/0000-0002-9347-

2 Tardieu, 2003; 2012.
} de uso y distribución Creative Commons Reconocimiento 4.0 Internacional (CC BY 4.0). 
cia de Quito, examiné las reacciones de los siervos frente a la administración de Temporalidades y a la venta de dichas tierras con sus dotaciones ${ }^{3}$. En las líneas siguientes, se evocarán los diferentes problemas enfrentados por dicha entidad para la gestión de la numerosa población negra de las propiedades de la orden en el Perú, en relación con los nuevos criterios de rentabilidad que se sustituyeron al «plan divino» manejado por los religiosos ${ }^{4}$.

El concepto de la esclavitud aplicado por los jesuitas en sus propiedades agropecuarias, cualquiera que fuera su destino, difería con mucho del de los particulares, preocupados por lo inmediato, en la medida en que éstos no disfrutaban de la complementariedad productiva que rebajaba el costo de la explotación ${ }^{5}$. Además, para los Padres, el progreso en la humanización de la servidumbre era por cierto una condición sine qua non para mejorar la producción, como apuntó Pablo Macera en 1977:

La importancia económica del esclavo determinó el desarrollo de una política por parte de sus amos tendiente a procurar el mejor rendimiento de la inversión realizada. Los jesuitas fueron en esto verdaderos maestros y precursores pues se ingeniaron en aplicar normas demográficas, morales, de alimentación y trabajo que de un lado les procuraban la lealtad del esclavo y del otro les garantizaban la eficacia de su esfuerzo ${ }^{6}$.

El mismo paternalismo, concepto que no dista del de «esclavitud relativa», evocado en 2015 por Maribel Arrelucea Barrantes y Jesús A. Cosamalón Aguilar $^{7}$, aparece de modo solapado en las instrucciones impartidas por los responsables de la Compañía a los administradores de sus haciendas en Nueva España, estudiadas en 1950 por François Chevalier8. Rosa María Martínez de Codes va más allá, tratando de las plantaciones de la orden en los dominios españoles y portugueses de América. Recalcó en 1995 que «la forma en que los jesuitas regularon este aspecto de la vida de los esclavos parece ser más humanitaria y más ajustada al espíritu y a la letra de las disposiciones conciliares $\rangle^{9}$. Se refiere la historiadora madrileña a los famosos concilios limeños.

Efectivamente, no se puede pasar por alto el hecho de que este manejo, tan llamativo desde un punto de vista económico, era también una exigencia

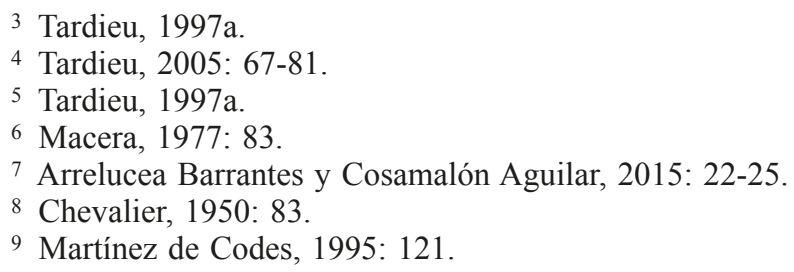


de su propio compromiso cristiano, lo cual, para ellos, no era ninguna contradicción, como intenté demostrarlo ${ }^{10}$. Es un aspecto a no perder de vista para entender la reacción de los esclavos cuando se enfrentaron a los nuevos criterios introducidos por la Administración de Temporalidades después de la expulsión de la Compañía.

\section{LOS ESCLAVOS JESUÍTICOS COMO MERCANCÍA}

El mayor problema que se planteó desde un primer tiempo a las Temporalidades fue el de la mano de obra. ¿Qué hacer con estas numerosas familias, conformadas a menudo por varias generaciones ${ }^{11}$ ? Los menores y los mayores eran de escasa productividad, y a veces de ninguna. En los informes de los administradores a la Dirección General viene con recurrencia la expresión algo cínica de «brazos inútiles», muy reveladora de su focalización. Rompiendo así los lazos familiares forjados por los Padres, se veían obligados a separarse de ellos, de varias maneras.

\section{Venta de los «brazos inútiles»}

Entre los «brazos inútiles», se encontraban los niños de poca edad, nacidos de las familias formadas por los jesuitas que solían casar a sus siervos lo más pronto posible. Eran los individuos más difíciles de vender, salvo a compradores en busca de jóvenes con el fin de plasmarles según sus exigencias. Estaban dispuestos incluso a pagar precios altos para satisfacerlas, como aparece en una venta del 18 de noviembre de 1773, efectuada con permiso del oidor de la Real Audiencia como fiscal de Temporalidades. Doña Manuela Falcón, por 260 pesos, adquirió a Celedonia, de ocho años de edad, de la hacienda San Juan ${ }^{12}$.

Con el tiempo, no desapareció el problema, prueba de la dificultad estructural experimentada por la Administración para asumir las consecuencias de la expulsión. El 7 de noviembre de 1815, el fiscal aceptó la proposición de doña Margarita Tenorio de comprar tres niñas depositadas en su casa, después de la avaluación hecha por don Manuel Antonio de Porras, corredor de lonja

\footnotetext{
10 Tardieu, 2005: 67-81.

11 Tardieu, 1997a.

12 Archivo General de la Nación, Lima (AGNL), Temporalidades (Temp.), legajo (leg.) 346, documento (doc.) 26.
} 
de Lima, el 29 de noviembre. Según declaración de la futura propietaria, Gregoria padecía de hidropesía y de garrotillo, lo cual era mucho para una negrita de ocho años, de ahí el moderado precio de 100 pesos. Otra niña, que no pasaba de 4 o 5 años, de constitución «feble», mereció parecida tasación. En cambio, la estimación de la sambita Rosa, de la misma edad, pero sin tachas particulares, alcanzó 200 pesos. En 2 de enero del año siguiente, se informó a doña Margarita de la cantidad, o sea 400 pesos, fijada para disfrutar de la «potestad domínica» sobre las tres esclavitas. El documento patentiza por cierto las precauciones tomadas por las Temporalidades para separarse de esclavos «de poca edad», máxime cuando tenían achaques posiblemente redhibitorios, pero principalmente la propensión de compradores de cortos alcances para adquirir esclavos a bajo precio cuando se ofrecía semejante oportunidad, desatendiendo los dramas familiares suscitados por estas transacciones, que nunca se verificaban en tiempos de los expulsos ${ }^{13}$.

La venta de los ancianos y de los «achacosos» adoptaba varias modalidades, motivadas por una cínica legalidad. Nunca la hubieran aceptado los regulares que se valían de sus servicios para quehaceres domésticos, por muy insignificantes que parecieran. El 1 ero de febrero de 1772, el director general decidió la enajenación de unos de ellos «a fin de evitar los gastos de manutencion, vestuario, curacion y el riesgo de vida, que en qualquiera de dichas casas lo padece el fondo de esta incumbencia». Al corredor mayor de lonja, don Joseph Xavier Esteban, con la ayuda del cirujano Francisco Portales, le tocó evaluar a dos esclavos. Javier, del colegio de San Pablo, de 45 años, tenía «un clavo de buba en la planta del pie derecho», lo cual le hacía inapto para el trabajo. El defecto de Joseph, del colegio del Cercado, era su edad: a los 60 años, no le quedarían fuerzas suficientes para desempeñarse en una hacienda de las Temporalidades. Les estimaron a cada uno a $200 \operatorname{pesos}^{14}$.

Se determinó el 21 de julio de 1780 la reventa de dos esclavos, vendidos en un primer tiempo para la construcción de un monasterio de monjas en Ica. Acabada la obra, se requirió el permiso de las Temporalidades para proceder a una nueva transacción. Francisco Ceballos padecía de una hernia intestinal en la ingle y Justo Bolaños tenía fuertes dolores en los hombros, consecuencia de un accidente ocurrido cuando era aserrador. Los dos «no eran capaces de trabajo fuerte», de ahí el moderado precio de 150 pesos por cada uno ${ }^{15}$.

Una obra pía no precisaba siempre pasar por la compra para disponer de esclavos achacosos de las Temporalidades. En 1772, la madre Melchora de

\footnotetext{
13 AGNL, Temp., leg. 346, doc. 103.

14 AGNL, Temp., leg. 238, doc. 5.

15 AGNL, Temp., leg. 346, doc. 42.
} 
Cristo, prepósita de la Real Casa de Amparadas de la Purísima establecida en la Casa de Retiro de San Felipe de Neri, anteriormente de los expatriados, gestionó el préstamo de «una u otra pieza de esclavos que por ser viejos son inútiles a las haciendas y de provecho para nuestro manejo interior». Más precisamente se trataría de dos mujeres para barrer la iglesia y la casa y de otras dos para la cocina y los menesteres de la casa. La Junta propuso un hombre y una mujer de las antiguas haciendas jesuíticas «inútiles a su cultivo». Por fin, el 10 de junio de 1772, el director general otorgó «dos negras por ser útiles para la servidumbre, la anciana nombrada María de San Josef y Theresa Gabriela por no ser a propósito para el laboreo de la hacienda ${ }^{16}$.

Al resolver Dionisio de Mesa, albacea del difunto Francisco Antonio Lastra, sacar al negro Francisco de la testamentaria, le fue menester recabar el asentimiento de las Temporalidades por haber pertenecido antes el siervo a los jesuitas. El motivo era que «este por el accidente habitual de reuma a los ojos [...] era impedido de poder servir en ningun destino, y, lexos de ser util a la testamentaria le trae regularmente crecidos gastos». Le correspondía pues «obviar la manutencion de un esclavo inutil». Por eso pidió al director general de Temporalidades que «con reflexion a su estado y enfermedad se tase y venda, porque a la testamentaria le es mas util qualesquiera cosas que den por el que mantenerlo sin provecho y con gasto». No tenía el esclavo más de 35 años, y sin embargo el tasador don Joseph Javier Estasio, corredor mayor de la lonja de Lima, le estimó tan sólo a 200 pesos el 16 de junio de 1778. El cirujano Francisco Portales informó el 15 de julio que estaba

... padeciendo de los dos ojos, esto es tener llagados y reversos los parpados inferiores. La enfermedad no es de peligro, y es curable. Ella se a haumentado y se a echo rebelde con la especie de trabajo a que esta reducido Francisco, pues consta de continuo fuego y de carga en la cabeza, y estos oficios le son perjudicados a su enfermedad.

La Dirección General esperó el 14 de octubre para oponerse a la enajenación de Francisco por el precio propuesto, sacándole a público remate ${ }^{17}$.

De todas formas, para cualquier reventa de esclavos pertenecientes antes a los regulares, según parece, hacía falta avisar a la administración de Temporalidades. Lo hizo el escribano Juan de Vargas Aliaga el 23 de junio de 1773, cuando don Félix Correa, vecino de Mendoza, vendió Lorenzo Justiniano a don Josef Aiscombe, sotasíndico de los Santos Lugares de Jerusalén, a falta del doctor don Thomás Muños, síndico, «que con otros varios compro

16 AGNL, Temp., leg. 342, doc. 11.

17 Ibidem, doc. 26. 
de la Real Junta de Temporalidades de la ciudad de Cordoba de Tucuman, sin asegurarlo de ningun vicio y tachas, defectos, enfermedad publicos ni secretos mas que al presente esta sano». Correa formaba parte de los especuladores que adquirían esclavos de las haciendas jesuíticas de la provincia de Córdoba para venderles en el Perú, como lo comenté en otra parte ${ }^{18}$.

Este comercio humano, que califiqué de «trata interna», imponía ciertas condiciones materiales específicas y requisitos administrativos, en particular al nivel fiscal, según el espacio en que se manifestaba, posponiendo las más veces la dimensión humana de sus víctimas.

\section{Traslados}

Para aumentar la rentabilidad de las haciendas y facilitar su integración en los criterios económicos corrientes, los administradores evitaban el subempleo de brazos productivos, máxime cuando se trataba de trabajadores con familia.

Traslados a otras haciendas del Perú

Entre 1768 y 1773, el ingenio de Huaura se benefició de la obra de mano excedente de varias haciendas. Su administrador, Felipe Antonio Negrín, avisó a la Dirección General el 4 de septiembre de 1768 de la entrega por el alférez Pedro Rosales de la negra Francisca Xaviera, de la samba Siriaca con su marido Joseph Toribio y una hija de ambos, de edad de cuatro años. Venían de la hacienda San Javier, en la provincia de Santa. El 25 de noviembre del mismo año, bajo vigilancia de Lucas Falcón, llegó, para «auxilio de esta hacienda» una pareja formada por Alexo de Castro y su mujer María Coronel, de la hacienda San José de la Pampa, en el partido de Santa. A juzgar por la referencia a «cuatro pares de bragas», se tomaron precauciones para evitar su escape. Un poco más tarde, o sea el 12 de diciembre de 1768, el mismo personaje declaró haber recibido a dos negros, llamados el uno Joseph Antonio Ávalos y el otro Joseph Mercado, pertenecientes al fundo San Javier. Por fin, dicho administrador estipuló el 8 de febrero de 1773 que el visitador general de Temporalidades, don Ramón de Moya y Villar, le había remitido 30 piezas de esclavos, criollos, congos y caravalíes, sobrantes de la hacienda de Tumán y pertenecientes al antiguo colegio de Trujillo. Tenían entre 4 meses y 60 años de edad, variando su valor de 50 a 500 pesos. El motivo de la decisión de

18 Tardieu, 2012: 105-110. 
apartar a estos siervos de Tumán había de buscarse en los desaciertos económicos de la finca desde la época de los jesuitas ${ }^{19}$.

En agosto de 1775, don Juan Joseph de Aguirre, vecino del valle de Palpa, declaró ante escribano público haber aceptado de la Dirección General de Temporalidades la misión de conducir «con prisiones y seguridades necesarias» a la hacienda San José de La Nazca a seis esclavos: Antonio de los Santos (40 años al parecer), Pedro Núñez (38 años), Joachím Pizarro (38 años) y su hija Anselma (3 a 4 años), la samba Petrona de Solís (40 años) y el sambo Matheo Oliva (10 a 12 años), hijo quizá de la precedente. Cumplido el encargo, entregó al tribunal de Temporalidades el correspondiente recibo despachado por el administrador de la hacienda, don Juan de Lobatón, devolviendo en el mismo tiempo las prisiones con que iban asegurados los esclavos. Reconoció haber cobrado por la conducción la cantidad de 96 pesos, 84 de los cuales correspondían a su salario y 12 a los alimentos de los siervos durante el viaje ${ }^{20}$.

Así la dirección procuraba por lo menos no separar a los miembros de una misma familia. Pero no se fiaba de la reacción de los siervos al apartarles de su hacienda de origen, como patentiza el uso de bragas y prisiones. Por añadidura se daban pasaportes a los conductores, para garantizar la legalidad de su actuación y obtener asistencia de las autoridades durante el traslado. Lo firmaba el propio director general. Valga el ejemplo siguiente:

A los señores guardas, corregidores, alcaldes y demas justicias, gefes y oficiales que de tal exercen desde la jurisdicion del correximiento del Cercado de esta capital hasta el distrito de la hazienda de Ninabamba que fue ocupada a los regulares expatriados del colegio de Huamanga.

Hago saber que para los fines y efectos en el fomento de dicha hacienda remitto con el arriero don Nicolas Afrian tres negros esclavos de otras que se destinan a aquella por conbeniente al servicio y son Juan de Portalatina, Joseph Antonio y Antonio de los Santos, para que no tan solamente se le ponga el menor tropiezo ni embargo en su conduccion, sino que en caso necesario de algun auxilio para efecto de su segura conduccion se le deis e imparteis por V. Sa y Vmds a dicho arriero conforme a la necesidad que pudiese ocurrir por ello, y que hara mencion con este oficio, que de parte de S. M. (que Dios guarde) prove para el fin expresado. En la Ciudad de los Reyes del Peru y octubre doce de mil setecientos setenta y dos. Cristobal Francisco Rodriguez ${ }^{21}$.

Cuando se enviaba a los esclavos a haciendas de la costa sur, se usaba la vía marítima. En el Callao, con fecha de 25 de abril de 1769, Antonio Loay-

19 Tardieu, 2008.

20 AGNL, Temp., leg. 342, doc. 21.

21 AGNL, Temp., leg. 346, doc. 22. 
za declaró haber recibido de la dirección de Temporalidades 32 piezas de esclavos, embarcados a bordo del Santo Tomás con destino al puerto de Pisco: 8 negros, 14 negras con 10 criaturas $^{22}$.

Traslados desde fuera

Los siervos procedentes de fuera del Perú venían de Chile o de Argentina. He aquí algunas referencias para el año 1768:

-El 8 de agosto, la administración de Temporalidades pagó 6 pesos 4 reales por el flete desde el Callao hasta Lima de 13 piezas de esclavos comprados por don Sebastián Sotera.

-El 4 de septiembre se abonó la cantidad de 19 pesos 2 reales por vestuario de 7 piezas procedentes de Chile.

-El 22 del mismo mes, se pagaron 324 pesos al agustino Fr. Agustín Camino, los 275 pesos «por el valor principal que satisfizo en Chile por un negro nombrado Lorenzo que compro y condujo a esta capital».

El 12 de noviembre de 1771, el doctor don Josef Villasanta, en nombre de don Ventura Andía, abonó 200 pesos por el mulatillo Fortunato de Jesús, recibido el 23 de junio de 1770 entre los que vinieron de Chile en el navío El Rosario. Se procedió a su venta porque se pensaba que su mezcla con los negros de las haciendas sería perjudicial. Y por si fuera poco sufría de «débil contextura» ${ }^{23}$. Así que la dirección se encargaba de todos los gastos originados por la llegada de esclavos para beneficio de sus haciendas, reembolsaba las cantidades pagadas por intermediarios, pero descartaba elementos posiblemente perturbadores o ineptos para las arduas faenas del campo. No faltan los ejemplos. En 7 de septiembre de 1770, el director general, con venia del fiscal y previa tasación, juzgó oportuno vender ciertas piezas de ambos sexos de las Temporalidades de Chile porque no eran «adaptables para las haciendas de este resinto por el diverso exercicio a que los regulares expatriados los tuvieron dedicadas en su tiempo» ${ }^{24}$. Ver tabla 1

22 AGNL, Temp., leg. 349, doc. 69.

23 AGNL, Temp., leg. 340, doc. 6.

${ }^{24}$ Ibidem, doc. 4. 
Tabla 1. Venta de esclavos no adaptables PRocedentes de Chile-1770

\begin{tabular}{|l|c|c|}
\hline \multicolumn{1}{|c|}{ Nombre } & Edad & Tasación \\
\hline Antonia, negra & 28 años & 425 pesos \\
\hline Marcelino, negrito, hijo de Antonia & 5 & 180 \\
\hline Juana Bentura, negra & 24 & 400 \\
\hline Ignacia de Jesús, negra & 16 & 375 \\
\hline María Isabel, negra & 14 & 350 \\
\hline Jacoba de la Cruz, negra & 30 & 400 \\
\hline Úrsula, negra, hija de Jacoba & 3 & 150 \\
\hline Antonio, zambito, hijo de Jacoba & 3 meses & 50 \\
\hline Pasquala, negra & 28 & 400 \\
\hline María Mercedes, negra, hija de Pasquala & 1 mes & 50 \\
\hline Lorenzo, negro & 8 & 200 \\
\hline Fortunato, negro & 8 & 200 \\
\hline Antonico de Jesús & 18 & 400 \\
\hline
\end{tabular}

Entre estos «brazos inútiles» recién importados de Chile, que muestra la tabla 1, varios debieron de nacer durante el viaje o poco antes. Obviamente, las Temporalidades de Chile, preocupadas por la rentabilidad, intentaban masculinizar sus dotaciones; y como las del Perú tenían el mismo propósito, no les quedaba más que acudir a la venta para deshacerse de estas jóvenes y de sus hijos. A veces eran familias enteras las que llegaban de la provincia vecina como aparece en un documento sin fecha. De Coquimbo vinieron el negro Eugenio de Loyola (25 años), con su mujer la negra Úrsula (20 años) y su hija, la mulatilla Francisca Paula (4 años); el negro Domingo (25 años); el negro Pablo (50 años) con su mujer, la negra María Rosa (35 años), y su hijo Bernardo, de pecho. De Valparaíso procedió Manuel Silva, negro soltero de 15 años $^{25}$. Esta última referencia patentiza el drama que significó para las familias de los fundos jesuíticos la expatriación de la Compañía. Las lanzó en un azaroso vagabundeo muy lejos de lo que considerarían como su tierra, y por fin se cernía por encima de ellas la amenaza de la cruel separación.

El tráfico daba lugar a un comercio especializado que les dejaba esperar interesantes beneficios a los mercaderes. Actuaban como intermediarios, como prueba la lista de la tabla 2, elaborada el 20 de julio de 1768 por el guarda mayor del puerto de Callao, quien intervino personalmente en esta lucrativa actividad.

25 AGNL, Temp., leg. 349, doc. 74. 
Tabla 2. Traslados de esclavos Desde Chile por vía Marítima (LISTA DE 20-VII-1768)

\begin{tabular}{|l|l|l|}
\hline \multicolumn{1}{|c|}{ Barcos } & \multicolumn{1}{|c|}{$\begin{array}{c}\text { Propietarios, } \\
\text { intermediarios o } \\
\text { consignatarios }\end{array}$} & \multicolumn{1}{c|}{ Negros } \\
\hline Sra. de las Mercedes & D. Joseph Ramírez & 15 hombres y mujeres \\
\hline N. Sra. de la Hermita & D. Joseph de Inchausti & $\begin{array}{l}5 \text { hombres y } 5 \text { mujeres con 4 hijos } \\
\text { de pecho }\end{array}$ \\
\hline N. Sra. del Socorro & D. Francisco Cusidor & 7 negros \\
\hline El Fuerte & D. Joseph Varela & $\begin{array}{l}1 \text { negro y 1 negra con 1 hijo de } \\
\text { pecho }\end{array}$ \\
\hline La Sacra Familia & Pablo Carreras Granada & 1 mulato \\
\hline
\end{tabular}

Llegados al Callao, se olvidaban a veces los intermediarios de presentar las piezas a la Dirección General de Temporalidades. El 28 de julio fue menester llamarle a la orden a don Joseph de Inchausti. Se le hizo saber su obligación por segunda vez, amenazándole el 9 de agosto con ponerle preso en la real cárcel de corte hasta cumplimiento de la reclamación. El incriminado contestó que había respetado la legalidad, cuando se había contentado con presentar 9 de las 14 piezas exigidas. Tres se vendieron a don Joseph Barbadillo, como constaba de una escritura expedida por escribano real, por 880 pesos y 20 pesos correspondientes a los derechos fiscales; y dos al conde de Casa Dávalos por 696 pesos y 4 pesos de derechos. El importe de las ventas alcanzaba 1576 pesos, de los cuales había que defalcar 598 pesos y 4 reales de los gastos de conducción a Valparaíso y luego a Lima, manutención, curación de algunas indisposiciones y demás «menudencias», y 310 pesos de «riesgo de mar» de Valparaíso al Callao. Sólo quedaban 667 pesos 4 reales. En cuanto entraron en su poder, como caudal suyo, los invirtió en la compra de efectos para Chile, remitidos en el navío El Fénix y las Mercedes. En cuanto al valor de los demás esclavos, lo llevaría él mismo a Valparaíso en La Hermita, de próxima salida, en que haría de piloto. Por eso solicitó, bajo fianza, un término de cuatro meses para abonar la deuda al regresar al Callao. Exigió la anulación de los 1400 pesos que pidió el guarda mayor del puerto como derechos sobre los 14 esclavos comprados en Santiago en remate público el 29 de mayo de 1768 por 3100 pesos. Por fin Inchausti se resolvió a pagar todas las tasas ${ }^{26}$.

26 AGNL, Temp., leg. 254, doc. 12. 
Los esclavos importados de Tucumán seguían el mismo camino, como significó el 8 de febrero de 1773 don Miguel de la Cabareda. En virtud de poder de don Domingo de Caxiga, vendió, después de reconocimiento por cirujano, a don Pedro Josef Bravo de Castilla, por 1894 pesos 6 reales de contado, 4 negros, nombrados Francisco, Alexo de la Cruz, Juan y Francisco, que el dicho Caxiga adquirió de las Temporalidades de Tucumán. Llegaron al Callao en el navío la Sacra Familia, ya referido más arriba.

Estos datos ponen de manifiesto la inserción de la venta de los negros de las Temporalidades de Chile y del Tucumán en la globalidad del circuito comercial, cuyos actores invertían en el acto el producto de las transacciones en la compra de efectos para una próxima venta en Chile. La importancia de los gastos, motivada en parte por graves riesgos, requería una rápida rotación que, en algunos casos, pasaban las tasas por alto. Pero las mayores víctimas, a no caber duda, no eran las arcas reales, sino estos individuos y familias «inútiles» bamboleados por los inclementes puertos de los Andes y las procelosas aguas del Pacífico. Pese al interés de los comerciantes en cuidar un mínimo de su salud física, de la cual dependía el precio de venta, poco les importaban su integridad síquica y el respeto de los lazos familiares forjados en las propiedades de la Compañía. De ahí los intentos de estos desgraciados de huir de la amenaza.

La gente «útil» que tenía la suerte de quedarse en los antiguos fundos jesuíticos, considerados por ellos como su tierra, veían sin embargo empeorar su vida, debido a las exigencias de la nueva gestión.

\section{NuEVAS EXIGENCIAS EN LAS HACIENDAS DE LAS TEMPORALIDADES Y FUERA}

No se evocarán aquí los informes levantados por los gerentes en nombre de las Temporalidades, que ya se han estudiado ${ }^{27}$. Sin embargo, quedan entre los papeles de dicha administración unos documentos relativos al devenir de los esclavos tras el secuestro, que ameritan nuestra atención.

\section{Algunos aspectos existenciales en las haciendas de las Temporalidades}

Es el caso de una encuesta, sin fecha, sobre la viña San Juan Bautista de Cóndor. Contestando a las preguntas de sus superiores, Joseph Quintana, suministra datos sobre la situación del fundo poco tiempo después de la ex-

27 Macera, 1966. 
patriación. A la sazón, contaba con 60 fanegas de viña y 108 esclavos y esclavas de todas edades. Por no resultar bastantes para las tareas se vio constreñido a contratar jornaleros. En verano, la gente se levantaba a las cinco de la mañana y en invierno a las seis. Acabada la oración, se dirigían al trabajo, según su especialidad, durante los seis meses de «labor». Después se dedicaban a las faenas de la pampa (cavar, empalar, podar y replantar).

Con el fin de mantener la hacienda en buen estado, adelantó Quintana, sería necesario introducir algunas reformas, como la de levantarse la gente a las cuatro de la mañana para trabajar de sol a sol, hasta rezar el rosario ${ }^{28}$. Así pues, el cambio de administración resultaría perjudicial para los trabajadores serviles, obligados en el porvenir a aumentar sus horas de trabajo.

No sería Quintana el único en mostrarse más exigente que los jesuitas, tras el abandono de sus criterios de gestión. Resulta difícil apreciar las consecuencias de las innovaciones introducidas, en particular con respecto a la salud de los esclavos. Hace tiempo, estudiamos detenidamente el sistema sanitario piramidal introducido por los padres para la atención de su gente, que iba de la enfermería de la hacienda hasta la del colegio máximo San Pablo, pasando por la del colegio propietario del fundo ${ }^{29}$. Si bien se mantuvo la de San $\mathrm{Pa}-$ blo, ya no le correspondía atender a los siervos de Temporalidades. En caso de necesidad, los administradores usaban los servicios del hospital de los negros San Bartolomé30, en Lima, como prueba la documentación. A fines de 1768, para el período del primero de septiembre de 1767 al 27 de noviembre de 1768 , o sea casi catorce meses, se estableció un cuadro reproducido en la tabla $3^{31}$.

\footnotetext{
28 AGNL, Temp., leg. 342, doc. 94.

29 Tardieu, 2007b.

30 Tardieu, 2002: 159-208.

31 AGNL, Temp., leg. 346, doc. 6.
} 
Tabla 3. Atención de esclavos de las Temporalidades en El hospital DE SAN BARTOLOMÉ

(1-IX-1767 A 27-XI-1768)

\begin{tabular}{|l|c|c|c|c|c|}
\hline \multicolumn{1}{|c|}{ Haciendas y colegios } & Entradas & Salidas & Muertes & Días & Pesos (1 día=4r) \\
\hline -Casa de Desamparados & 9 & 8 & 1 & 430 & 215 \\
\hline -Colegio del Cercado & 1 & 1 & 0 & 27 & $13 \mathrm{p} \mathrm{4r}$ \\
\hline -Chacarita San Bernardo & 2 & 2 & 0 & 106 & 53 \\
\hline -Dirección & & & & & \\
\hline -Noviciado & 4 & 4 & 0 & 58 & 29 \\
\hline -Humaya & 2 & 2 & 0 & 46 & 23 \\
\hline -San Juan Francisco Regis & 3 & 2 & 1 & 482 & 241 \\
\hline -Ingenio de Huaura & 1 & 1 & 0 & 32 & 16 \\
\hline -Vilcahaura & 1 & 0 & 1 & 74 & 37 \\
\hline -Santa Beatriz & 140 & 135 & 5 & 1898 & 949 \\
\hline -San Pablo & & & & & \\
\hline -Villa & 23 & 21 & 2 & 713 & $356 \mathrm{p} \mathrm{4r}$ \\
\hline -San Juan & 42 & 39 & 3 & 632 & 316 \\
\hline La Calera & 13 & 13 & 0 & 186 & 93 \\
\hline Colegio San Pablo & 3 & 2 & 1 & 70 & 35 \\
\hline Total & 244 & 230 & 14 & 4754 & 2377 \\
\hline
\end{tabular}

Las haciendas solicitaban más el hospital San Bartolomé que lo hacían los colegios, donde había poco personal, y los pequeños fundos como la chacarita San Bernardo. En cambio parece algo extraño que la gente de Santa Beatriz, cuya dotación no pasaba de 144 individuos después de la expatriación, necesitara en catorce meses 1898 días de hospitalización, cuando Villa, que constaba de 377 esclavos $^{32}$, no pagó más de 713 días de atención, y San Juan Francisco Regis, con 304 siervos, no abonó más de 412. ¿Sufrió la dotación de Santa Beatriz los estragos de una tremenda epidemia? No habría sido la única. Los excesos de las nuevas pautas serían más perjudiciales en este lugar, sin que se pueda afirmarlo de un modo taxativo.

En el Ingenio de Huaura, con una dotación de 296 esclavos según los registros del secuestro, el capellán señaló haber enterrado a 10 de ellos entre el 28 de abril y el 13 de octubre de 1768 , o sea cinco meses y medio ${ }^{33}$. Parece mucho, mayormente si comparamos esta cifra con otras posteriores. Para 1772, el ca-

\footnotetext{
32 Tardieu, 2003: 61-109.

33 AGNL, Temp., leg. 350, doc. 5.
} 
pellán mercedario se refirió tan sólo a la muerte de una anciana de 86 años y de un párvulo. En 1774, falleció una negra de la hacienda en el hospital San Bartolomé34. ¿A qué se debe esta diferencia? ¿No le fue particularmente nocivo el primer año de la gestión de Temporalidades para la gente de Huaura?

\section{Reivindicaciones después de la venta de los «brazos inútiles»}

Una vez vendidos fuera de las haciendas, los esclavos se enfrentaban a una realidad desconocida, muy a menudo despiadada. Valga la experiencia de María Josefa Caravalí, de 60 años de edad. Le compró en 1772 por 100 pesos el licenciado Narciso Henrríquez para ponerle a la disposición de su amante doña María del Carmen Bellido. Como se dio cuenta la sierva de las relaciones ambiguas de la pareja, el clérigo se puso a maltratarle, echándole la comida a la cara, tratándole de perra y diciéndole que empedraría su casa con sus huesos. Harta de tantas sevicias, María Josefa, acogiéndose a la ley, quiso cambiar de amo. No lo aceptó doña María, amenazándole con venderle en Pisco después de castigarle en una panadería. Henrríquez subió su precio a 170 pesos, a sabiendas de que nadie los daría por una vieja quebrada que echaba sangre por la boca. Frente a la protesta de la esclava, le espetó que de todas formas nadie le creería por ser él sacerdote. De puro miedo, María Josefa huyo de casa e intervino ante el director general de Temporalidades, implorando el reconocimiento de un cirujano. Estaban dispuestos sus cuatro hijos y sus dos nietos, aseguró, a pagar los 100 pesos de la anterior evaluación de modo a lograr su libertad. A doña María del Carmen, se le notificó la orden de dejarle ejercer sus derechos, de lo cual hizo caso omiso. La justicia quitó a María Josefa de la panadería donde estaba presa para colocarle en casa de don Joseph de Andía y Varela que aceptó pagar la fianza adecuada y los jornales debidos al ama. El 24 de julio, se depositaron los cien pesos prometidos entre las manos de una tercera persona, y, por fin, los aceptó doña María del Carmen ${ }^{35}$.

No pensaría María Josefa que, a su edad, la expulsión de los jesuitas le acarrearía tales desgracias. Por lo visto, no faltaban quienes se aprovechaban de la expatriación para adquirir esclavos por poco precio con el fin de satisfacer sus veleidades. No se desanimó la esclava, atreviéndose a reclamar la protección del mismo director general, el cual no huyó de sus responsabilidades.

No siempre se mostró tan benévolo, es verdad, para con los esclavos que pretendían su socorro. Lo hizo Juana Portocarrero en Lima el 17 de agosto

\footnotetext{
34 AGNL, Temp., leg. 349, doc. 30.

35 AGNL, Temp., leg. 258, doc. 16.
} 
de1752. También quiso imponer su venta a su ama, Doña Juliana Portocarrero, pensando tener el dinero suficiente para rescatarse. De creer a la sierva, la dueña no dejaba de fijar un precio excesivo con el único propósito de «molestarle», es decir de obstaculizar su proyecto de alcanzar la libertad, aumentando cada vez el importe de la tasación inicial. Convencida de que no tenía pruebas de su señorío, Juana se dirigió a la Real Audiencia, precisando que nació en la hacienda San Juan de los expatriados jesuitas. De las investigaciones en los archivos resultó el 28 de agosto que, a los 3 o 4 años, le vendieron entre una partida de 45 esclavos proveniente de dicha hacienda. Le adquirió por 200 pesos doña María de Cárdenas, la cual transfirió luego su dominio a Doña Juliana Portocarrero ${ }^{36}$. Por lo tanto, ésta podía disponer de ella, sin intervención posible de parte de Temporalidades. Pero de esta respuesta se deducirá que no se desinteresaban de la suerte de los antiguos esclavos de la Compañía, ejerciendo una especie de patronato jurídico.

A los ancianos pasados a dominio particular, les correspondía acudir al tribunal supremo, cuando tenían la posibilidad, para intentar poner fin a los maltratos. La gente en buen estado físico poca suerte tenía de suscitar la piedad de los oidores, únicamente atentos al respeto de la legalidad. Caso de no poder aguantar más, sólo le quedaba la huida para protegerse de los excesos infligidos por los nuevos amos.

\section{FUGAS}

Se ha aludido más arriba a las fugas de varios esclavos, deseosos de no pasar o no permanecer bajo poder extraño, como si temieran efectos perjudiciales para su propia existencia. La documentación estudiada expone las condiciones de estas huidas y de su represión, lo cual da lugar a veces a auténticos discursos de vida de profunda significación. Se singularizan en comparación con el tradicional cimarronaje que se manifestaba por todas las Indias occidentales ${ }^{37}$.

\section{Circunstancias}

Al enterarse de su enajenación, unos de estos esclavos se las arreglaban para desaparecer. El 19 de noviembre de 1795, protestó con vehemencia

\footnotetext{
36 AGNL, Temp., leg. 266, doc. 17.

37 Para el Perú, ver: Bowser, 1977: 242-279. Tardieu, 1987. Aguirre, 2005.
} 
Francisco Próspero Solís Bango. Transcurridos cinco meses tras la compra del esclavo Ignacio de Jesús, de la hacienda La Huaca, con el compromiso de no traspasarle - condición muy excepcional, notemos de paso - todavía no había conseguido ponerle la mano encima. Según supo, el fugitivo se ocultaba en la misma hacienda, sin duda con la complicidad de sus compañeros o familiares. El dueño exigió de la dirección de Temporalidades la entrega del esclavo a un miembro de la Junta para que él pudiese recogerle. Se dieron órdenes de satisfacer su demanda ${ }^{38}$.

A la sazón, casi treinta años después de la expulsión de los regulares, Ignacio de Jesús sería un hombre mayor, con buen conocimiento de la topografía del fundo que le permitía escapar de cualquier persecución. Esta situación patentizaba tanto la falta de medios adecuados por parte del administrador para cumplir con su obligación, o su inepcia, como la solidaridad entre trabajadores serviles suscitada por los lazos trabados quizá desde hacía decenios. Éste es, por lo tanto, un auténtico caso de cimarronaje interno.

Muy parecida fue la actitud de Francisco, de la hacienda de Bocanegra, unos veinticinco años antes. Huyó de su comprador don Pedro Josef Bravo de Castilla para volver a su tierra. Pero, por motivos desconocidos, no gozó de la misma suerte que Ignacio de Jesús. Consiguieron detenerle en la hacienda, poniéndole en la real cárcel de corte antes de remitirle al alcalde ordinario para su entrega al hermano de don Pedro Josef ${ }^{39}$.

Dada la preocupación de los jesuitas por la formación y la defensa de las familias en sus propiedades, que se manifestaba por todo el continente ${ }^{40}$, el apego al terruño y a la familia motivaba también la fuga de los esclavos trasladados a otra hacienda lejana. Un documento sin fecha se refiere a la huida de trabajadores de Villa destinados a «auxiliar»a los de Belén y La Nazca. Se ocultaban en el totoral de los alrededores de la hacienda o en edificios poco concurridos. Bonifacio y Fabián se habían refugiado en el molino, donde su compañero Joseph Colorado les proveía de comida cada 24 horas. No debió resultar muy difícil seguirle los pasos. En cambio, desde hacía varios meses se le había perdido la pista a Joseph Inocencio, siendo preciso transmitir su señalamiento a las autoridades: soltero, de buena presencia, tamaño regular... ¡Y se añadió que se ignoraba la causa de su huida! Estos datos muy superficiales no facilitarían su búsqueda. Llegados a la hacienda San José de La Nazca, varios de los trasladados escaparon para aproximarse a Villa. Se halló

\footnotetext{
38 AGNL, Temp., leg. 266, doc. 28.

39 AGNL, Temp., leg. 349, doc. 32.

40 Para el Perú, ver: Martín, 1968. para Ecuador, ver: Tardieu, 1997a. Para Venezuela, ver: Torres Sánchez, 2001: 112. Para México, ver: Konrad, 1980: 28.
} 
en Lima a tres huidos, Antonio Chabuque, Marcos y Cayetano, y a otros dos, Juan de Dios y Joseph Polonio, cerca de la hacienda de Ica (¿cuál?) ${ }^{41}$.

En ciertas haciendas, como la de Villa, las mujeres no se quedaron atrás para expresar su disconformidad en cuanto a los avatares de su nueva existencia. El 11 de noviembre de 1800 un grupo de 14 esclavas se apersonó en la Dirección General de Lima huyendo del maltrato y de los castigos impuestos por el presbítero doctor don Bernabé Tramarria a quien su padre, don Pedro, le había confiado el fundo arrendado a Temporalidades. La víspera, a Josefa Agapite, preñada de 3 o 4 meses, le hizo azotar después de retirarse del trabajo a las seis de la tarde. La gota colmó el vaso, siendo frecuentes los excesos de su parte. En los días pasados, las sevicias ${ }^{42}$ les dejaron incapacitados para el trabajo a 4 negros nombrados Inocencio, Eusebio, Manuel y Juan Antonio. El clérigo mantuvo a 3 de ellos en el cepo por no presentarse para las faenas, y el otro se huyó. El charqui de la comida estaba lleno de gusanos, y no les quedaba otro remedio a los esclavos que hurtar productos de las chacras próximas, de ahí las protestas de los dueños y otros castigos. La dirección no desconocía las consecuencias de tal manejo, pero sus anteriores advertencias quedaron sin efecto. Esta vez, las negras requirieron medidas de manera que la hacienda no se acabase «con los domésticos». El responsable pasó el expediente al provisor de la diócesis para que, como superior del sacerdote, encontrara una solución. El día siguiente, se aproximó a las oficinas otro grupo conformado por 12 negras y 14 negros con el propósito de denunciar la venganza de Tramarria. Les había quitado su poca ropa y sus utensilios de cocina, incluso las ollas, amenazándoles con hacer degollar los cochinos de sus chiqueros con que mejoraban lo ordinario.

Avisado, el propio virrey ordenó el 13 de noviembre a Pedro Tramarria que recibiese a los fugitivos sin infligirles la menor pena, devolviéndoles cuanto les había quitado. En su respuesta del 14, don Pedro les acusó de abultar los moderados castigos de modo a mover a compasión al director y llamar la atención del virrey. Sin embargo se declaró dispuesto a cumplir las órdenes conforme volviesen los desertores a sus respectivas labores donde se

\footnotetext{
41 AGNL, Temp., leg. 349, doc. 73.

42 En estos últimos años, abundan los estudios sobre las condiciones de existencia de los siervos en todas las Indias occidentales, e intentos de comparación con las provincias inglesas. Este trabajo no da cabida para evocarlos. Ver: Genovese, 1981. Diremos tan sólo que, hace poco, se presentó una explicación sicoanalítica según la cual «la agresividad del amo se interpreta como un mecanismo de defensa de éste en relación con el sentimiento de inferioridad (temor interno) que experimentaba respecto al esclavo», Munive, 2008: 100.
} 
les suministraría «como siempre se ha executado un sustento mas que competente» ${ }^{43}$.

¿Cambió de actitud el avariento clérigo? El documento no proporciona información al respecto. Lo que sí se puede deducir es que él y su padre - no serían los únicos en hacerlo -, vieron en el arrendamiento de las antiguas haciendas jesuíticas una oportunidad de ganar dinero en poco tiempo por disponer de una abundante mano de obra sumisa. Era sin contar con el surgimiento de una toma de conciencia de su fuerza colectiva por parte de la dotación, suscitada por las mujeres como madres responsables del mantenimiento de los hogares. Las esclavas de Villa, a no caber duda, desempeñaron un papel nada desdeñable en la evolución de las reivindicaciones serviles en el Perú, en un contexto estudiado por Christine Hünefeldt y Maribel Arrelucea Barrantes ${ }^{44}$. Nos preguntaremos si no debían en parte al manejo jesuítico este protagonismo, es decir esta proclividad a emplear, como dijo Rachel Sarah O'Toole ${ }^{45}$, «their position as catholics» para valerse de los tribunales y de las leyes coloniales, aspecto que ilustró también su lucha por la libertad, como señalaremos más abajo.

Por lo menos, haciendo abstracción de su indefensión, supieron valerse de la legalidad para apelar a la protección real, consecuencia lógica del secuestro de los bienes de la Compañía. Si no faltaron las protestas en contra de la Administración de Temporalidades, bien conocidas ahora, ésta sin embargo era un mal menor comparándola con la gestión privada que incurría en lo arbitrario por cuestión de rápido rendimiento.

\section{Represión}

Se necesitaban casos de semejante gravedad para que la dirección de Temporalidades se dejara apiadar, siendo su finalidad, fijada por la misma Corona, mantener la productividad de las antiguas haciendas de la Compañía.

Frente a la multiplicación de las huidas, no podía menos de reaccionar so pena de ver derrumbarse el sistema servil que se ambicionaba preservar pese al abandono de las normas jesuíticas. Para acabar con esta sangría que podía hacerse letal, la administración utilizaba el sistema de señalamiento a que se ha aludido más arriba para los fugitivos de Villa destinados a la hacienda San

\footnotetext{
43 AGNL, Temp., leg. 342, doc. 69.

44 Hünefeldt, 1984: 155; 1994. Arrelucea Barrantes, 2009: 57-73.

45 O'Toole, 2013: 1110.
} 
José de La Nazca. Los indicios facilitados a las autoridades locales eran de escasa utilidad como lo da a entender el documento siguiente de 1768:

Negros uhidos de la Haz ${ }^{\text {da }}$ de S. Jph de la Nasca

-Fabian, alto de cuerpo, buena cara, delgado, mozo, casado en la misma haz ${ }^{\mathrm{da}}$ con Maria de los Santos.

-Cayetano, pequeño de cuerpo, de carnes regulares, mozo, soltero y este y el anterior tienen ponchos de cordellate.

-Marcos, del cuerpo de Fabian, delgado. Le faltan los dientes de la parte superior, mozo, soltero.

Se uyeron de la $\mathrm{Haz}^{\mathrm{da}}$ en mediados de julio con corta diferencia y vinieron en su seguimiento dos negros de $\mathrm{S}^{\mathrm{n}} \mathrm{Jph}$ nombrados Anselmo, Victoriano de Ihs y Patricio de la Haz da ${ }^{\text {de }}$ Belen $^{46}$.

Aunque no se puede sacar determinadas conclusiones a partir de tan corta lista, nos preguntaremos si los fugitivos no eran más bien jóvenes solteros o recién casados sin hijos. La vida no les había quitado todavía la esperanza de cambiar las cosas. En cuanto a los mayores, o no se sentían la fuerza de enfrentar drásticas dificultades, o, sacando lecciones del pasado, se mostraban escépticos en cuanto a su posibilidad de acertar en contra del sistema represivo. Según el documento, se confió la búsqueda de los cimarrones a tres congéneres suyos, que les conocerían bien por pertenecer a los mismos fundos. Esta misión plantea un problema, el de la solidaridad dentro de las dotaciones, que no dejaba de ejercerse como se ha dicho. No faltarían pues excepciones, originadas por contingencias humanas de varias índoles, como desavenencias o ambiciones personales, a no ser que dichos persecutores se las arreglaran para cumplir lo mínimo.

Fuera lo que fuere, acababan a menudo los fugitivos por caer entre las manos de la fuerza pública, de lo cual se avisaba al director general. Valga el ejemplo de Joseph Inocencio, evocado renglones arriba, como consta en el documento siguiente relacionado con casos de los años 1768 y 1769:

-Recibi en esta $\mathrm{R}^{1}$ Carsel de corte una negra nombrada Maria Pascuala del Espiritu Santo de orden de $\mathrm{d}^{\mathrm{n}}$ Francisco Rodriguez director $\mathrm{g}^{1}$ de temp ${ }^{\mathrm{des}}$ y la encargo Santiago de los Rios arriero de la carrera del Callao y para que conste di este mi recibo en 16 de abril de 1768. Rosendo Valverde.

-Queda en mi poder un negro nombrado Faustino Ballejo, perteneciente a la Hacienda de la Guaca por el orden del Sor Don Christoval Rodriguez al que doy recibo. Cassa y 25 de febrero de 1769. Christobal Zambrano.

\footnotetext{
46 AGNL, Temp., leg. 349, doc. 70.
} 
-Queda en esta panadería un negro nombrado Manuel Ylarde por orden del $\mathrm{s}^{\mathrm{r}}$ Don Christoval Francisco Rodriguez. Cassa y Marzo 21 de 1769. Christobal Zambrano.

-He recibido de el sr Dn Christobal Francisco Rodriguez Director General de Temporalidades hun negro nombrado Joph Inocencio perteneciente a la hacienda de Belen, en Yca el que tendre a disposicion de dho Sr. Lima y Marzo 11 de 1769.

Trajo dicho negro una braga corriente con la que queda preso y dha braga pertenece a la hacienda de San juan en donde se prendio. Zambrano.

-Queda en esta panadería de mi cargo Clemente Queraposo, preso por orden del dr D. Christoval Rodrigues. Lima 21 de marzo de 1769. Zambrano.

-Queda en esta $\mathrm{R}^{1}$ Carcel de corte de mi cargo Benancio Ranson de orden del $\mathrm{S}^{\mathrm{r}} \mathrm{D}^{\mathrm{n}}$ Cristobal Rodrigues director gral de temporalidades. Lima 3 de febrero de 1777. Jph Viz ${ }^{\text {te }}$ del valle ${ }^{47}$.

Una vez cogidos, se mandaba a los fugitivos a dos lugares, la real cárcel de corte o una panadería, donde las duras condiciones laborales servían de pena para los esclavos reacios. El traslado desde el lugar de captura se confiaba a un arriero, el cual no podía ejecutar su misión sin utilizar «bragas» o sea prisiones. Según parece Cristóbal Zambrano, dueño de uno de estos «amasijos», se encargaba de la vigilancia de los detenidos por orden de Temporalidades. Merced a su recibo nos enteramos de que se ubicó a José Inocencio entre la dotación de la hacienda San Juan donde encontraría asistencia de parte de sus conocidos.

Por no hacer al caso, los breves informes suministrados a la administración por los encargados de su captura y de su castigo no se explayaban en la existencia de los prófugos. En cambio, para quienes consiguieron pasar inadvertidos por varios motivos durante un largo lapso de tiempo, la justicia se veía obligada a determinar con exactitud el encadenamiento de los hechos hasta remontar a sus orígenes.

\section{El discurso de vida de un cimarrón}

Arrestado por don Juan Valdés en 1774, Miguel Arnedo, de su verdadero nombre Gregorio, se encontró preso en la real cárcel de corte desde el 24 de enero. Llevaba 18 años fuera de la hacienda de Vilcahuaura, habiendo huido antes de la expatriación de los regulares. Detenido por la justicia en la villa de Tarma, le dieron por amo a don Juan Joseph de Arnedo, sin más indagaciones, lo cual resultaba sospechoso. Trabajó tanto para él que llegó a que-

\footnotetext{
47 Ibidem, doc. 6.
} 
brarse de la ingle derecha, pero su estado no le impidió abonarle los dos reales y medio diarios de su jornal.

En su declaración, Gregorio expuso un verdadero discurso de vida. De 45 a 48 años de edad, dijo ser de origen congo. Sacado por los ingleses de su tierra en «Guinea», o sea en África, fue conducido con otros muchos a Panamá48, donde le compró el jesuita Martín de Mendizábal ${ }^{49}$. Éste le envió a Piura por el puerto de Paita. Camino de Lima, oyó hablar de la destrucción de la ciudad por un temblor, lo que le permitió fechar su llegada por el año 1746. Le mandaron directamente a la hacienda de Vilcahuaura con varios esclavos comprados por el padre Martín cuyos nombres recordó sin dificultad alguna. Allí seguía su padrino de bautismo, Josef Mabino. Luego le confinaron en el ingenio de Huaura, donde sus padrinos - de confirmación suponíafueron Alberto Chala y Petrona Matoso. También conoció a Francisco Xavier, desterrado después por los jesuitas a la hacienda de Bocanegra. Él sí que podría confirmar su pertenencia a Vilcahuaura.

En dicha finca se desempeñó como negro de lampa hasta el año de 1758 o los primeros meses de 1759, momento en que escapó. Cuando le raptaron, no era casado «entre los españoles», pero «sí estaba recién casado a su modo en Guinea». Esta rápida alusión introduce patetismo en el discurso. Gregorio se mostró capaz de recordar la vida en la hacienda, marcada por las oraciones en la capilla todos los sábados y los días festivos por la noche, donde se llamaba a los esclavos por padrón. Después de su huida, el destino le llevó para las serranías del Cuzco, a ocho o diez leguas del pueblo de Tarma donde sufrió mucho del frío, de la lluvia y de la nieve. De pasar adelante correría el riesgo de quedar helado, le advirtió un arriero, aconsejándole que le siguiese hasta Tarma, una buena tierra. A los cuatro días de estar en el pueblo, le mandó prender el gobernador don Pablo Sáenz de Bustamante. Poco después le llevaron a un obraje en el que actuó como preso durante más de un año. Luego le devolvieron al pueblo cuyo nuevo gobernador, don Antonio de Ozes y Bustamante, le envió a otro obraje donde permaneció más de un año. Tras de lo cual le vendieron en Tarma a don Juan Josef de Arnedo, quien le nombró Manuel Arnedo pese a sus protestas. Se llamaba Gregorio y pertenecía a

48 Es de precisar, sin embargo, que se detuvieron las actividades de la Compañía inglesa del mar del Sur desde 1739 hasta después del tratado de Aquisgrán de octubre de 1748.

49 Para la compra de esclavos por los jesuitas del Perú en Panamá, ver: Tardieu, 2004; 2017. El padre Martín de Mendizábal recibió de la hacienda San Jerónimo en enero de 1745, 184 peruleras de aguardiente para, con su valor, adquirir esclavos destinados al colegio San Pablo. 
la hacienda de Vilcahuaura, no dejaba de repetir, suscitando amenazas de rigurosos castigos si reincidiese.

Aseguró Gregorio no conocer al mercedario Fray Manuel de Cartagena, ni menos a doña Cipriana de Peralta ni a su marido don Juan Antonio Salvarria ni a su hijo don Juan Ignacio que pretendieron haberle comprado a dicho fraile. Por orden de don Francisco Xavier de Arnedo le pusieron en la panadería de don Hermenegildo Tovilla después de la muerte de don Juan Josef de Arnedo.

Habiendo comprobado la justicia las aseveraciones de Gregorio, el director general de Temporalidades prescribió el 14 de febrero de 1775 su depósito en la hacienda de Bocanegra o en la de Villa. Se suministró el expediente a don Francisco Xavier de Arnedo el 20 de marzo de 1775, informando también al gobernador de Tarma ${ }^{50}$.

Así pues, Gregorio fue víctima de quienes se proponían poner la mano sobre cimarrones para transformarles en esclavos suyos, sin gastar ni un real, a sabiendas de que no denunciarían la estafa. Con la complicidad de conocidos suyos, no vacilaban en elaborarles una falsa biografía. Para salir de apuros, Gregorio se vio en la necesidad de reivindicar su pertenencia a la hacienda de Vilcahuaura. Su declaración ilustra las vicisitudes padecidas por los bozales desde su llegada al Nuevo Mundo y las desgracias sufridas por los cimarrones de las haciendas jesuíticas que corrían el riesgo de encontrarse entre Escila y Caribdis.

La huida, como se acaba de ver, no carecía de peligros que amedrentarían a los más cohibidos. Sin embargo, para los siervos de los ignacianos, fuera de las rebeliones de que no hablaremos por ser un tema muy conocido ya ${ }^{51}$, quedaba otro medio de alcanzar la tan anhelada libertad.

\section{LIBERTAD}

La expulsión de los jesuitas, se puede presumir, dio esperanzas a no pocos de sus esclavos de lograr su libertad de un modo legal, aprovechando las contradicciones de la administración de Temporalidades, ansiosa de rentabilidad.

\section{Concesión colectiva de libertades después del secuestro}

En cuanto llegó a los oídos de los siervos de la Compañía la posibilidad de rescatarse después del secuestro, muchos de ellos probaron hacerlo. Usaban

\footnotetext{
50 AGNL, Temp., leg. 259, doc. 12.

51 Kapsoli, 1975.
} 
los que podían la mediación de un abogado para levantar su solicitud a la Dirección General de Temporalidades. Se agruparon por ejemplo unos trabajadores de la hacienda San Javier de La Nazca el 10 de noviembre de 1769 con la asistencia de Luis de Mesa. Se trataba de Prudencio de Jesús, Martina del Águila, Fernanda de Jesús, Julián de la Rosa y Estefanía Pizarro. A pesar de estar dispuestos a comprar su libertad después de la debida evaluación, pretendieron, «no hubo lugar por entonces su pretencion a causa de no hauer facultades algunas en aquella oportunidad para ser admitida». Pero se difundió el rumor en días pasados de la desaparición de los obstáculos, de ahí su demanda de tasación que no dejó de plantear un problema para la explotación de la hacienda. El director, según aseveró el 29 de noviembre, confiaba que, con la llegada de esclavos trasladados de Chile, se podría asegurar su fomento. Al fin y al cabo el fiscal dio su visto bueno el 7 de diciembre de 1769 .

Como premio de su buen comportamiento, arguyó Julián de la Rosa, los administradores jesuitas de la hacienda les habían concedido «algunos pedazos de tierra para sus cortas sementeras de aji y algodon que sin perjuicio de dicha hacienda laboreaba en los intervalos de horas de su descanso y algunas festividades». Se trataba de las conocidas «chacras» o «conucos». Así recogió hasta unos 500 pesos con la finalidad de obtener su libertad, como se la confirieron los padres a algunos de sus compañeros. Incluso se lo prometieron, lo cual no pudo concretarse con la ocupación de la hacienda y el extrañamiento de los regulares.

Consiguieron convencer al fiscal de Temporalidades Pedro de Echeverría, al director general Cristóbal Francisco Rodríguez y al virrey Manuel de Amat. El 19 de diciembre de 1769 dictaminaron la evaluación de los ocho esclavos. El 8 de marzo de1770 se nombró como tasadores a don Marcos Pacheco y a don Juan Josef Muños, asistidos por don Josef Gorozabal, profesor de medicina.

Entrando en confianza, algunos esclavos se mostraron más exigentes. Fernanda de Jesús propuso también para la tasación a su hijo Joseph Fulgencio, párvulo de 21 días de edad, lo cual se aceptó en el acto. María del Patrocinio, que no formaba parte del grupo, obtuvo su admisión el día siguiente. El médico le encontró «alguna enfermedad interior de mucha gravedad, porque su contextura es de un esqueleto». En cuanto a los demás, todos se hallaban sanos. Ver tabla 4. 
Tabla 4. San Javier de La NazCa-Tasación (9-III-1770)

\begin{tabular}{|l|c|l|c|}
\hline \multicolumn{1}{|c|}{ Nombre } & Edad & \multicolumn{1}{c|}{ Tachas } & Tasación \\
\hline Martina de Águila & 41 & & $340 \mathrm{p}$ \\
\hline Fernanda de Jesús, samba & 26 & & $400 \mathrm{p}$ \\
\hline Gaspar de los Reyes & 26 & de poca fuerza & $425 \mathrm{p}$ \\
\hline Ventura de Jesús & 21 & de contextura débil & $425 \mathrm{p}$ \\
\hline Estefania Pisarro & 37 & & $360 \mathrm{p}$ \\
\hline Estefania de Jesús & 16 & & $400 \mathrm{p}$ \\
\hline Isabel de Portugal & 50 & & $230 \mathrm{p}$ \\
\hline María de la Concepción & 34 & de contextura débil & $300 \mathrm{p}$ \\
\hline María del Patrocinio & 40 & se halla hecho un esqueleto & $125 \mathrm{p}$ \\
\hline Josef Fulgencio, hijo de & 21 & & $50 \mathrm{p}$ \\
Fernanda de Jesús & días & & \\
\hline
\end{tabular}

En agosto de 1770 se procedió a la tasación de esclavos de otras haciendas que la pidieron. Ver tabla 5.

TAbla 5. SAn José de La Nazca-TASación (29-III-1770)

\begin{tabular}{|l|c|l|c|}
\hline \multicolumn{1}{|c|}{ Nombre } & Edad & \multicolumn{1}{|c|}{ Tachas } & Tasación \\
\hline Rosa de Santa María & 35 & baldada de un brazo & $400 \mathrm{p}$ \\
\hline Tiburcio Coronado & 40 & $\begin{array}{l}\text { quebrado, con una hernia } \\
\text { completa }\end{array}$ & $180 \mathrm{p}$ \\
\hline Teodora de Castro & 57 & & $300 \mathrm{p}$ \\
\hline Josefa Calixto & 22 & quebrada, con hernia ombilical & $125 \mathrm{p}$ \\
\hline Micaela Jiménez & 37 & $\begin{array}{l}\text { con una fístula en el ano y } \\
\text { fiebre }\end{array}$ & $350, \mathrm{p}$ \\
\hline Rosa Mora & 36 & & $180 \mathrm{p}$ \\
\hline Úrsula Pérez & 60 & & $150 \mathrm{p}$ \\
\hline Justa Máxima & 34 & manca de un brazo & $100 \mathrm{p}$ \\
\hline $\begin{array}{l}\text { Patricia de los Dolores, } \\
\text { mulata, párvula, hija de Justa }\end{array}$ & 3 & & 200 \\
\hline Anselmo de San Marcos & 60 & defectuoso de un brazo & \\
\hline
\end{tabular}

El 5 de agosto de 1770, se añadió a Cayetano de Jesús. Con fractura en la clavícula derecha, fue tasado a 350 pesos. El 12 de agosto de 1770, se le encargó al visitador de las haciendas de La Nazca y de Ica la notificación a 
los tasados de que se les proporcionarían «los instrumentos de libertad» en cuanto exhibiesen en las cajas reales la cantidad de su tasación ${ }^{52}$.

Así que los responsables de Temporalidades aceptaron atender las súplicas de no pocos esclavos de estas haciendas, y de otras sin duda alguna. ¿Tomaron en cuenta las supuestas promesas hechas por los jesuitas de otorgarles la libertad a ciertos de ellos? Éstos no solían hacerlas. Pero lo seguro es que dichos siervos no podían rescatarse sin el fruto del trabajo en las chacras concedidas por los regulares. Y conste que la cantidad exigida no era poca, a veces más de 400 pesos. Obviamente no faltaban los esclavos de los fundos agrícolas de la Compañía que disfrutaban de un indudable poder económico, a cambio, es verdad, de toda una vida de alienación. Si la Administración de Temporalidades prefirió satisfacer estas demandas para eliminar así los «brazos inútiles», no perdió dinero.

\section{«La libertad tan amable» a cambio de una vida de servidumbre}

Transcurrido algún tiempo, no cesaron las concesiones de libertad por motivos parecidos, pero se hicieron de manera individual. Esperaban los esclavos haber reunido el dinero suficiente para su demanda. María Dominga de Aguilar, de la hacienda San Juan Francisco Regis, una vez tasada por los peritos, se presentó en las cajas reales el 18 de noviembre de 1771 para pagar los 400 pesos exigidos ${ }^{53}$.

Muy conmovedor es el caso de Regina Mandinga, de la misma hacienda. Con el sostén de una tercera persona, posiblemente un abogado, se dirigió a la Dirección General de Temporalidades:

Regina Mandinga, negra esclaba de la hacienda de Sn Juan Francisco Regis, puesta a los pies de V. E. con su maior sentimiento, dice que de edad de diez años entro a ser esclaba de los jesuitas expatriados y en dicha hacienda en la que ha existido mas de cinquenta años y hallandose ya de edad de mas de sesenta postrada y con bastantes accidentes ha sido tasada por los peritos que a este fin fueron nombrados en dicha hacienda quando se abaluo el fundo en cien pesos y habiendosele proporcionado entre los de su parentela que le den esta cantidad para que con ella solicite su libertad tan amable entre los que nunca la han gozado que no obstante de ser por la ancianidad y accidentes en que la suplicante se ve costreñida pudiese considerarse en la posesion de este beneficio ${ }^{54}$.

\footnotetext{
52 AGNL, Temp., leg. 237, doc. 7.

53 AGNL, Temp., leg. 258, doc. 10.

54 AGNL, Temp., leg. 346, doc. 19.
} 
Ni siquiera tuvo la oportunidad, pese a cincuenta años de trabajo en la hacienda que le valieron muchos achaques, de reunir los cien pesos pedidos. Quizá por serle necesario criar a varios hijos, los cuales se mostraron agradecidos dándole el gusto al final de su vida de gozar de la libertad. La solidaridad familiar compensó la suma pobreza de la anciana.

El 1 de julio de 1771, se le concedió satisfacción. Regina, es de imaginar, no se demoró para dirigirse a la oficina de un escribano público. Pero éste le rechazó so pretexto de que era imprescindible una orden del director general para establecer la carta de libertad. La anciana la obtuvo el 17 de noviembre. Fueron cuatro meses y medio de espera que, a su edad, le parecerían una eternidad. Por fin, el 23, pudo disfrutar de la «libertad tan amable».

El rescate se efectuaba a veces desde el exterior de la hacienda, cuando el consorte era libre, por ejemplo. Así en 1774, Diego de la Cruz, marido de Melchora de los Santos, negra anciana de la hacienda de Vilcahuaura, actuó a favor de su esposa:

... ha tenido deseos de aliuiar a su mujer de las dolencias que padece sacandole de la esclavitud, y con cuio objeto ha procurado economizar de su trabajo y agencias hasta doscientos y cinquenta pesos en que se halla valorizada, no obstante su crecida edad, merito de muchos años de servicio y accidentes y enfermedades que padece... ${ }^{55}$

Se comprobaron los dichos de Diego de la Cruz, admitiéndose el 21 de abril de 1774 que la anciana no tenía «otra servidumbre que la de asistir en la enfermería de la mencionada hacienda». Lo más interesante viene luego: «... por otra parte es acreedora por su dilatado seruicio a obtener la gracia que su marido solicita por medio de la exuiuision de su importe...» Todo pasa como si fuera su liberación un premio, una manifestación de benevolencia por los servicios prestados a la colectividad, cuando en realidad era onerosa. El virrey Amat, para justificar su decisión, tomó el argumento en consideración, dando su beneplácito «en atención a su edad anciana y dilatada servidumbre». El 17 de junio de 1774, Juan de la Cruz, sambo libre, pagó los 250 pesos que concretaban un amor que no habían aminorado el tiempo y la distancia: le regalaba a su esposa el sueño de toda una vida.

\section{CONCLUSIÓN}

Encargada de la gestión de los bienes de los jesuitas después de la expulsión, la Administración de Temporalidades en el Perú, como en otras partes,

\footnotetext{
55 Ibidem, doc. 13.
} 
aplicó los criterios comúnmente admitidos, basados en el concepto de rentabilidad. Así que la posibilidad de rescatarse ofrecida a los «brazos inútiles», como había de esperar, no fue ninguna prueba de benevolencia. Los precios fijados por las tasaciones, efectuadas merced a gente experimentada con el parecer de médicos, no tenían nada que ver con una rápida liquidación.

Los esclavos así manumitidos, a no caber duda, no hubieran logrado la libertad, sin la expulsión. Pero sin los medios de producción y de ahorro puestos a su alcance por la Compañía, cualquiera que fuera su motivación, no pudieran aprovechar la oportunidad. El manejo jesuítico dio a los siervos de la orden una capacidad económica que gozarían poquísimos de sus compañeros de los fundos seglares. Por otra parte, merced a la política familiar instaurada por los regulares en pro de sus dotaciones serviles, existía una solidaridad que no dejó de expresarse con estos rescates personales. Fueron el resultado a menudo de muchos años de trabajo y de privaciones motivados por el amor filial o conyugal.

A los más atrevidos de quienes no podían beneficiarse de tales circunstancias, sólo les quedaba la fuga para lograr la «libertad tan amable». En este caso, también disfrutaban de la solidaridad familiar, suscitando un cimarronaje interno o de proximidad. Escogieron la misma alternativa ciertas víctimas de los traslados a otro fundo, manifestando así un sentimiento del que tratamos a propósito de la Real Audiencia de Quito, el apego al terruño, arraigado en el trato jesuítico.

En algunos casos, la Dirección General de Temporalidades ejercía una especie de tutela, o más bien de patronato, para con los esclavos de las haciendas arrendadas e incluso a favor de los siervos vendidos a particulares, actuando entonces el director en nombre del rey, a quien apelaban los damnificados por los abusos de los nuevos dueños. Aspecto muy moderno para la época, las mujeres desempeñaban un papel de primera importancia en las reivindicaciones colectivas.

Dicho esto, la venta de «brazos inútiles», al nivel local, fue una auténtica ganga para los amos en busca de niños o de ancianos, menos reacios a la explotación servil. A una escala más amplia, se integró, merced a lo que llamamos la «trata interna» ${ }^{56}$, en una red comercial, activando los intercambios con el cono sur. Fuente de pingües beneficios a cambio de indudables riesgos, daba lugar a conflictos entre el fisco real y codiciosos comerciantes.

Al fin y al cabo, la expulsión de los jesuitas, con el secuestro de sus bienes y en particular de su abundante mano de obra servil, como anticipación

56 Tardieu, 2012. 
de las reformas borbónicas relativas a la esclavitud (libertad del comercio de esclavos concedida por cédula de 28 de febrero de 1789, Instrucción para la educación, trato y ocupaciones de los esclavos de 31 de mayo de 178957), dio fin al sistema jesuítico, calificado indebidamente de paternalista cuando correspondía en gran parte, por más que se dijera, a una visión espiritualista del mundo. Numerosos «siervos de los Padres», poniendo aparte a los que se las arreglaron para sacar provecho de la ruptura merced a los medios suministrados y la formación inculcada por los expatriados, o a su propia fuerza de carácter, se vieron así proyectados de repente en un mundo extraño, cuyas exigencias de rentabilidad inmediata acentuaban su deshumanización o, mejor dicho, su instrumentalización.

\section{BIBLIOGRAFÍA}

Aguirre, Carlos, Breve historia de la esclavitud en el Perú. Una herida que no deja de sangrar, Lima, Fondo Editorial del Congreso del Perú, 2005.

Arrelucea Barrantes, Maribel, Replanteando la esclavitud. Estudio de etnicidad y género en Lima borbónica, Lima, Cedet, 2009.

Arrelucea Barrantes, Maribel y Cosamalón Aguilar, Jesús A., La presencia afrodescendiente en el Perú. Siglos XVI-XX, Lima, Ministerio de Cultura, 2015.

Bowser, Frederick P., El esclavo africano en el Perú colonial. 1524-1650, México, Siglo Veintiuno, 1977.

Chevalier, François, Instrucciones a los hermanos jesuitas administradores de haciendas. Un manuscrito mexicano del siglo XVIII, México, Universidad Nacional Autónoma de México, Instituto de Historia, 1950.

Genovese, Eugene D., «Le traitement des esclaves dans différents pays: problèmes d'application de la méthode comparative», Sidney W. Mintz, Esclave=facteur de production. L'économie politique de l'esclavage, París, Dunod, 1981: 172-183.

Hünefeldt, Christine, «Esclavitud y Familia en el Perú en el siglo XIX», Revista del Archivo General de la Nación, 7 (Lima, 1984): 147-162.

Hünefeldt, Christine, Praying the Price of Freedom. Family and Labor among Lima's Slaves. 1800-1854, Berkeley, University of California Press, 1994.

Kapsoli, Wilfredo, Sublevaciones de esclavos en el Perú. s. XVIII, Lima, Universidad Ricardo Palma, 1975.

57 Lucena Salmoral, 1996: 95-123. 
Konrad, Herman W. A., A Jesuit Hacienda in Colonial Mexico. Santa Lucia. 15761767, Wisconsin, The University Press, 1980.

Lucena Salmoral, Manuel, Los códigos negros de la América española, París/Alcalá de Henares, Ediciones Unesco/Universidad de Alcalá, 1996.

Macera, Pablo, «Instrucciones para el manejo de las Haciendas Jesuitas del Perú (ss. XVII-XVIII)», Nueva Corónica, II/2 (Lima, 1966): 49-127.

Macera, Pablo, «Los jesuitas y la agricultura de la caña», Trabajos de Historia, III (Lima, 1977): 69-107.

Martin, Luis, The Intellectual Conquest of Peru. The Jesuit College of San Pablo. 1568-1767, New York, Forham University Press, 1968.

Martínez de Codes, Rosa María, «De la reducción a la plantación. La utilización del esclavo negro en las haciendas jesuitas de la América española y portuguesa», Revista Complutense de Historia de América, 21 (Madrid, 1995): 85-122.

Munive, Moisés, «Blanco seguro: el maltrato a los esclavos en Cartagena y Mompox durante el siglo XVII», Procesos Históricos, 13 (Bogotá, 2008): 97-116.

O’Toole, Rachel Sarah, “As Historical Subjects: The African Diaspora in Colonial Latin America History”, History Compass 11/12 (Irvine, 2013): 1094-1110.

Tardieu, Jean-Pierre, «Le marronnage à Lima (1535-1650): atermoiements et répression», Revue Historique, CCLXXVIII/2 (París, octubre-diciembre 1987): 293-319.

Tardieu, Jean-Pierre, Noirs et Nouveaux Maîtres dans les “Vallées sanglantes” de l'Equateur, (1778-1820), París, L'Harmattan, 1997a.

Tardieu, Jean-Pierre, Los Negros y la Iglesia en el Perú. Siglos XVI-XVII, Quito, Centro Cultural Afroecuatoriano, 1997b.

Tardieu, Jean-Pierre, «San Bartolomé y Santa Ana: la salud de los afroperuanos en Lima a fines de la colonia», Boletín del Instituto Riva Agüero, 29 (Lima, 2002): 159-208.

Tardieu, Jean-Pierre, «Los esclavos de los jesuitas del Perú en la época de la expulsión (1767)», CMHLB Caravelle, 81 (Toulouse, 2003): 61-109.

Tardieu, Jean-Pierre, «Compra de esclavos por el colegio jesuita de San Pablo. Lima (1691-1729)», Hispania Sacra, 56 (Madrid, 2004): 241-258.

Tardieu, Jean-Pierre, «La esclavitud de los negros y el plan de Dios: la dialéctica de los jesuitas del virreinato del Perú», Sandra Negro y Manuel M. Marzal, Esclavitud, economía y evangelización. Las Haciendas jesuitas en la América virreinal, Lima, Pontificia Universidad Católica del Perú, 2005: 67-81.

Tardieu, Jean-Pierre, «La gestión de los esclavos en la hacienda jesuítica de Tumán (Perú. S. XVII-XVIII)», Summa Historiae, II/2 (Lima, 2007): p.n.c. 
Tardieu, Jean-Pierre, Los esclavos de los Jesuitas del Río de la Plata (Paraguay), 1767. Historia de una dramática regresión, Saarbruck, Editorial Académica Español, 2012.

Tardieu, Jean-Pierre, La compra de esclavos por el noviciado jesuítico San Antonio Abad. Lima (s. XVII y XVIII), Lima, Cedet, 2017.

Torres Sánchez, Jaime, Haciendas y posesiones de la Compañía de Jesús en Venezuela. El Colegio de Caracas en el siglo XVIII, Sevilla, CSIC/Universidad de Sevilla/Diputación de Sevilla, 2001.

Fecha de recepción: 11 de octubre de 2017.

Fecha de envío de las modificaciones: 18 de diciembre de 2017.

Fecha de aceptación: 11 de enero de 2018.

\section{Temporalities Administration of the slaves of former Jesuit haciendas (Peru, 1768-1815). Some socio-economic aspects}

The economic power of Jesuit slaves in Peru permitted some of them to buy their freedom after the expulsion. Attachment to their home soil among the victims of the transfers to other domains of the Temporalities often led runaways to remain close by. The sale of "useless arms" became part of a commercial network that extended throughout the Southern Cone.

In cases of abuse of slaves on rented haciendas or slaves sold to individuals, Temporalities provided a kind of patronage. In that respect, women played a very important role in collective claims.

Key words: Peru; Jesuits; expulsion; slaves; Temporalities administration; 1768-1815. 